\title{
Decomposing the Economic Costs and Benefits of Accession to the EU: the Swiss Case
}

\author{
Jean-Marie Grether and Tobias Müller* \\ University of Geneva
}

\begin{abstract}
This paper proposes a decomposition of the likely effects of a "deep" regional integration arrangement for a small country. It is based on a steady-state general equilibrium model which allows to capture the long-term effects of a variety of factors, including the reduction of non-tariff barriers, immigration, budgetary transfers and monetary integration. Particular care is given to the modeling of wealth accumulation, with savings endogenized on the basis of an overlapping generation framework. The effects of product standardization in manufacturing are simulated on the basis of ex-post estimates of the pro-competitive effects of the Single Market Program.
\end{abstract}

- JEL Classifications: F12, F15, C68

- Key Words: Regional Integration, Applied General Equilibrium

\section{Introduction}

Since the refusal of the European Economic Area (EEA) treaty by the Swiss voters in 1992, the Swiss government followed a triple stage strategy to pursue integration with the European Union (EU). In the short run, it adopted a series of unilateral measures aimed at bringing Swiss regulations closer to European ones. In the long run, although it had to freeze its candidacy, it never abandoned mem-

\footnotetext{
*Corresponding Address: Département d'économie politique, University of Geneva, $40 \mathrm{Bd}$ du Pont-d'Arve, 1211 Geneva 4, Switzerland Tel: +41-22-705-82-73, Fax: +41-22-705-82-93, Email: Jean-Marie.Grether@ses.unige.ch, responsible for correspondence and proofs.

Département d'économétrie, University of Geneva, 40 Bd du Pont-d'Arve, 1211 Geneva 4, Switzerland Tel: +41-22-705-82-38, Fax.: +41-22-705-82-99, Email: Tobias.Mueller@ metri.unige.ch. (c)2001-Center for International Economics, Sejong Institution, All Rights Reserved.
} 
bership of the EU as its ultimate objective. In the medium run, a less ambitious partnership was negotiated with the EU whose obligations, known as the "Bilateral Agreements", have been accepted by a Swiss referendum in May 2000. Although the debate goes beyond economic issues, it is of crucial importance to understand the economic consequences of these strategies. What are the likely economic effects for Switzerland of staying out, getting closer (through the bilateral agree-ments) or of joining the EU? This paper proposes a simulation model which iden-tifies the various channels through which European integration is likely to affect resource allocation and welfare. Its distinguishing characteristic resides in the variety of effects that are incorporated in the model and the decomposition of these effects.

Several dimensions of the Swiss case make it particularly interesting, and applicable to other applicants for membership. First, Swiss protection is still considerable in the case of agricultural goods and food products. The adoption of the Common Agricultural Policy (CAP) in the case of EU accession would thus imply drastic changes in the protection of these sectors. Second, at present wage differentials, free labor movement would lead to a net immigration flow. This will have important consequences for both aggregate welfare and income distribution, depending not only on the total amount, but also on the skill composition of the immigrant population. Third, fiscal compliance with EU rules would mean an important contribution to the EU budget and a shift from direct to indirect taxation. Official estimates show that if the net transfer to the EU was financed by an increase of the rate of the value added tax (VAT) to the European minimum level, this would generate additional resources, allowing a reduction in the income tax rate. Fourth, a substantial increase in interest rates can be expected if Switzerland participates in the European Monetary Union (EMU). Indeed, the elimination of the exchange rate risk should make it impossible to maintain lower interest rates than in other European countries.

While not all of these effects necessarily concern countries seeking membership in the EU, they broadly apply to the new entrants of the recent enlargement and, to a lesser extent, they are also pertinent to countries like the Czech Republic, Hungary and Poland that are currently negotiating membership. Indeed, including the effects of the CAP, the VAT, as well as labor and capital mobility is necessary if one wishes to capture orders of magnitude of membership accession into a deep regional integration scheme. This paper proposes such a framework and applies it to the case of Switzerland. 
The simulation model has been designed with these issues in mind, and has two specificities. First, it reproduces a steady-state equilibrium where investment and savings decision are explicitly modeled, the latter on the basis of an overlappinggenerations framework of the "perpetual youth" type (Blanchard, 1985). Savings and capital formation are therefore endogenous, which is essential to capture the long-run impact of fiscal reforms or changes in capital mobility on both aggregate welfare and economic activity. Taking into account the degree of international capital mobility is of special concern for a country like Switzerland where net foreign assets are a substantial part of national wealth. Second, integration in the product markets is carefully modeled. Whenever possible, ex-post (econometric) estimates of the impact of the Single Market Program (SMP) are used as a benchmark for parameter values. This is particularly true for the imperfectly competitive sectors, which are modeled along the lines of previous studies of the SMP (see e.g. Haaland and Norman, 1992). Standardization is assumed to increase product substitutability, as in Harrison et al. (1996). However, rather than imposing an arbitrary change in parameter values, we calibrate the variation of the elasticity of substitution on the decrease in price-cost margins estimated ex-post by Allen et al. (1997).

A number of additional characteristics of the model are also worthwhile mentioning. First, the size asymmetry between Switzerland and the EU is a potential problem. It is unrealistic, in the case of differentiated products, to assume that such a small country produces the entire range of varieties of a good. Therefore, we account for the existence of non-competing imports in each imperfect competition sector in Switzerland. Second, to capture the redistributive dimension of reforms, we consider four labor categories, according to the skill level. Third, for a certain number of Swiss sectors which are excluded from the VAT base, investment would be penalized by an increase in indirect taxation. To control for this effect, the VAT in these sectors has been modeled, not only as a tax on final consumption, but also on intermediate consumption and investment.

Finally, regarding trade in non-agricultural goods, changes for Switzerland will probably be more limited than those experienced in the past by other European economies. A free trade agreement was signed with the EU in 1972. Moreover, since 1994, the "Swisslex" program has brought important parts of Swiss law so close to EEA law that technical barriers to Swiss-EU trade have been considerably reduced. Thus, in this area, it can be expected that Switzerland would gain less from full EU membership than EU countries did from the Single Market Program 
(SMP), a factor that has also been taken into account in the simulations and the calibration of the model. ${ }^{1}$

These distinguishing features of the model are described in Section II, while a more detailed description on data sources and calibration procedures can be found in the Appendix. Simulations and their results are presented and discussed in Section III. To anticipate one important result, it turns out that EU accession (without monetary union) or the more limited bilateral agreements lead both to an aggregate net welfare gain of the same magnitude (1-1.2\% of Swiss GDP). However, the former includes the Swiss contribution to the EU budget, which generates by itself an important welfare loss, and motivates a careful decomposition of all the effects at work. Final comments follow in Section IV.

\section{The Model}

The model includes three regions of unequal size: Switzerland, the EU and the Rest of the World (ROW), which is the relevant disaggregation to study the impact of preferential agreements from the standpoint of a single country. There are 26 sectors, with the main industrial sectors modeled in imperfect competition and increasing returns to scale (see Table A2). To capture the effects of budgetary transfer, we assume a balanced government budget. As for many countries joining the EU, there is a size asymmetry between Switzerland and its two big partners, which requires appropriate modeling of likely terms of trade effects. For sectors under perfect competition, we assume that products are differentiated by country (or region) of origin and destination (the usual "Armington" assumption). It is well known that in this framework, the small country's term of trade changes induced by trade liberalization are unrealistically strong and tend to dominate welfare effects (Brown, 1987). To avoid this problem, we assume very high elasticities of substitution (or transformation) between domestic and foreign goods in the two large regions: EU and ROW (see Table A1). For sectors under imperfect competition, goods are assumed to be differentiated at the firm level. At the usual levels of aggregation, this assumption would lead to an underestimation of the calibrated market power of Swiss firms, because goods from the small country have minuscule shares in the large regions. To avoid such an outcome, each sector

\footnotetext{
${ }^{1}$ An additional factor is the harmonization of public procurement and competition policies, which is also susceptible to generate welfare gains. Although not considered here, the inclusion of these effects in simulation models deserves further interest.
} 
is subdivided into sub-sectors, assuming that only a small (and exogenous) share of the product range is produced by Swiss firms (whereas firms in the EU and ROW cover the whole range of products).

\section{A. Equilibrium in the Product Market}

Separability assumptions for technology are depicted in Figure 1. Value added and intermediate inputs are combined using a Leontief aggregation function. Different labor skill levels are considered as they may play an important role in the case of immigration. To account for the empirically well-established complementarity between capital and high skilled labor and the substitutability between capital and low-skilled labor (see Hamermesh, 1993), the different skill levels enter the value-added function twice. First, a "Labor composite 1" (LC1), which is biased towards higher skills, is combined with capital. Second, the resulting aggregate (capital-LC1) factor is further combined with a "Labor composite 2" (LC2), biased towards lower skills. ${ }^{2}$

In (sub-) sectors with imperfect competition, each symmetric firm is assumed to produce its own variety of the good. For a firm of country (region) $c$ producing good $i$, total cost is given by:

$$
t c_{i}^{c}=m c_{i}^{c}\left(x_{i}^{c}+f c_{i}^{c}\right)
$$

Figure 1. Production Technology.

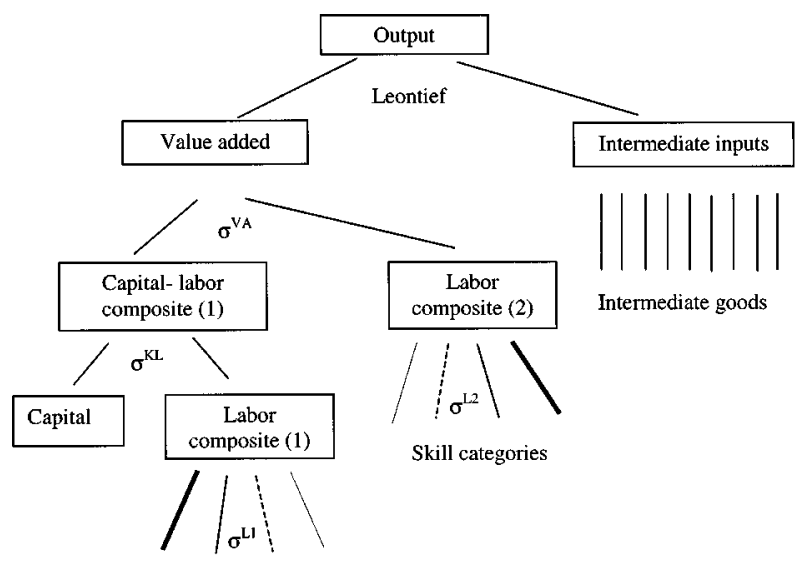

Skill categories

\footnotetext{
${ }^{2}$ The higher skill category (university) only enters LC1 while the lowest skill category (compulsory school) only enters LC2. The intermediate skill categories are allocated between the two labor composites as follows: $2 / 3$ in LC 1 and 1/3 in LC 2 for superior education; $1 / 3$ in LC 1 and 2/3 in LC2 for apprenticeship (see Table A.1 for the calibrated values of elasticities of substitution).
} 
where $t c$ is total cost, $m c$ marginal cost, $f c$ fixed costs and $x$ the volume of output of the individual firm. ${ }^{3}$ This functional form, chosen for simplicity, implies that fixed and variable costs have an identical input composition. Marginal cost is a function of a price index of value added, and of a price index of intermediate inputs corresponding to the structure of production shown in Figure 1. Imposition of the zero-profit condition, reflecting the assumption of free entry ${ }^{4}$, determines the number of firms in each sector.

Markets are assumed to be segmented, so that a firm from country $c$ chooses a different price for each market $d, p_{i}^{c d}$ (net of the output tax rate in country $c$ ). Under Cournot competition, profit maximization yields the usual equation for the markup on a variety of good $i$ produced in country $c$ and sold in country $d$ :

$$
\mu_{i}^{c d} \equiv \frac{p_{i}^{c d}-m c_{i}^{c}}{p_{i}^{c d}}=\frac{1}{\varepsilon_{i}^{c d}}
$$

where $\varepsilon_{i}^{c d}$ is the absolute value of the elasticity of demand in country $d$ for a variety of good $i$ produced in country $c$.

We assume that firms consider total expenditure as given, and perceive

Figure 2. (a) Preferences before Integration, (b) Preferences after Integration.

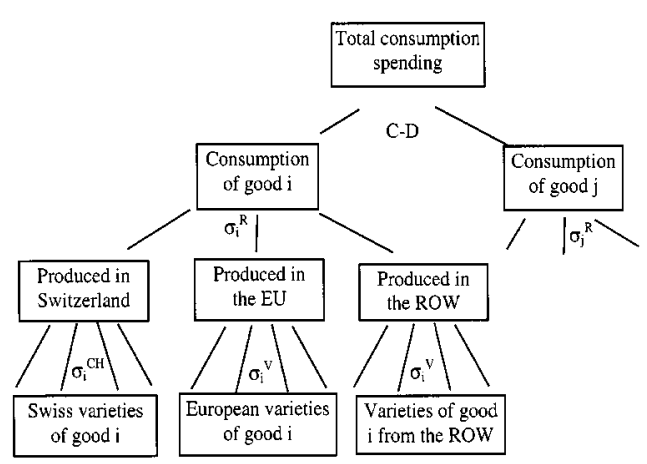

(a)

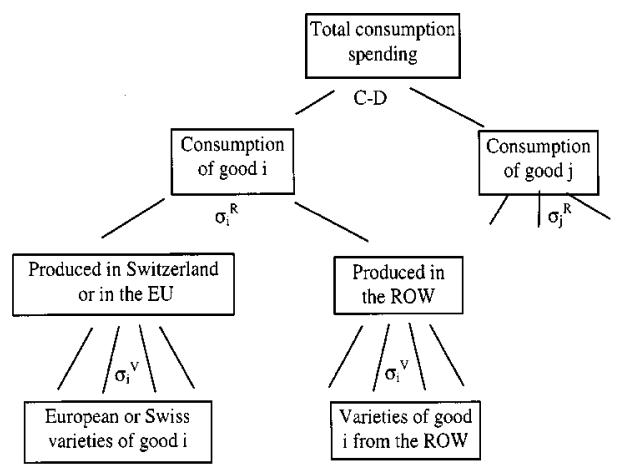

(b)

${ }^{3}$ The production function dual to [1] has the following form:

$$
x_{i}^{c}= \begin{cases}g_{i}^{c}-f c_{i}^{c} \text { if } & g_{i}^{c}>f c_{i}^{c} \\ 0 & \text { otherwise }\end{cases}
$$

where $g_{i}^{c}$ is a nested CES function having the structure depicted in Figure 1.

${ }^{4}$ Although frequent in such exercises, this convention leads probably to an underestimation of the procompetitive effects of integration, and might be replaced by an explicit treatment of the collusion between firms (e.g. along the lines of Mercenier and Schmitt, 1996). 
correctly the structure of preferences, which is the nested CES utility function represented in Figure 2. It can be interpreted as a multiple-stage budgeting process with an increasing elasticity of substitution at each step: first a choice is made between goods $(\sigma=1)$; then between regions of origin $\left(\sigma_{i}^{R}\right)$; and finally across varieties $\left(\sigma_{i}^{C H}, \sigma_{i}^{V}\right)$. Before integration, (Figure 2(a)), consumers perceive Switzerland and the EU as different regions, due to differences in regulations and technical standards. Integration modifies the structure of preferences (Figure 2(b)), increasing the substitutability between products on two counts. First, Swiss and European products are now perceived as originating from the same region. Second, to reflect the fact that standardization of products would be reinforced in Switzerland, it is assumed that, prior to integration, $\sigma_{i}^{C H}<\sigma_{i}^{V}$, with integration resulting in $\sigma_{i}^{C H}=\sigma_{i}^{V}$.

This integration-driven increase in substitutability is reflected in a higher perceived demand elasticity which leads to a fall in markup. It can be shown that, prior to integration, the perceived elasticity of inverse demand (or markup) is given by:

$$
\mu_{i}^{c d}=\left\{\begin{array}{c}
\frac{1}{\sigma_{i}^{C H}}+\frac{1}{n_{i}^{c}}\left(\frac{1}{\sigma_{i}^{R}}-\frac{1}{\sigma_{i}^{C H}}\right)+\xi_{i}^{c d} \text { if } c=d=\text { Switzerland } \\
\frac{1}{\sigma_{i}^{V}}+\frac{1}{n_{i}^{c}}\left(\frac{1}{\sigma_{i}^{R}}-\frac{1}{\sigma_{i}^{V}}\right)+\xi_{i}{ }^{c d} \text { otherwise }
\end{array}\right.
$$

where $n_{i}^{c}$ is the number of firms producing good $i$ in country $c, \xi_{i}^{c d}=\left(s_{i}^{c d} / n_{i}^{c}\right)$ $\left(1 /\left(1 / \sigma_{i}^{R}\right)\right)$ and $s_{i}^{c d}$ is the share of products from country $c$ in country $d$ 's total consumption of good $i$ 's products.

After integration, the markup becomes:

$$
\mu_{i}^{c d}=\frac{1}{\sigma_{i}^{V}}+\frac{s_{i}^{c r d}}{n_{i}^{c}}\left(\frac{1}{\sigma_{i}^{R}}-\frac{1}{\sigma_{i}^{V}}\right)+\xi_{i}^{c d}
$$

where $s_{i}^{\text {crd }}$ is the share of products from country $c$ in country $d$ 's consumption of good $i$ 's products from a "region" $r$ (the region being either Europe, including Switzerland and the EU, or the ROW). ${ }^{5}$

Hence, with a constant number of firms and constant market shares, the change in markup induced by increased substitutability is given by:

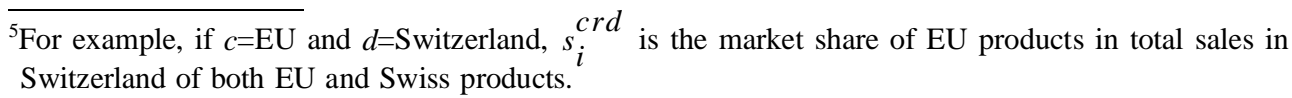




$$
\Delta \mu_{i}^{c d}=\left\{\begin{array}{lc}
-\left(1-\frac{1}{n_{i}^{c}}\right)\left(\frac{1}{\sigma_{i}^{C H}}-\frac{1}{\sigma_{i}^{V}}\right)-\frac{\left(1-s_{i}^{c r d}\right)}{n_{i}^{c}}\left(\frac{1}{\sigma_{i}^{R}}-\frac{1}{\sigma_{i}^{V}}\right) & \text { if } c=d=\text { Switzerland } \\
-\frac{\left(1-s_{i}^{c r d}\right)}{n_{i}^{c}}\left(\frac{1}{\sigma_{i}^{R}}-\frac{1}{\sigma_{i}^{V}}\right) & \text { otherwise }
\end{array}\right.
$$

Note that for ROW firms exporting to Switzerland or the EU, there is no change in the perceived demand elasticity with integration, since $s_{i}^{\text {crd }}=1$ in this case. The calibration procedure, described in Appendix B, combines equation [5] with the econometric estimates by Allen et al. (1997) of the fall in markup generated by the SMP, in order to calibrate the substitution elasticities that appear in Table A1.

\section{B. Equilibrium in the Capital Market}

To simulate the effects of the integration process in the long run, the determination of the stock of capital is of crucial importance. Investment and savings, and thus the aggregate stocks of capital and wealth, are modeled in a dynamic framework; though only the long-run (steady-state) equations are used in the numerical model. ${ }^{6}$

Consider first the determination of the demand for capital (country subscripts are dropped, unless necessary). In the steady state and in the absence of adjust-ment costs, capital demand of a representative firm in sector $i$ and country $c$ is determined by the equality between the marginal product of capital and the rental rate:

$$
\frac{\partial g_{i}}{\partial K_{i}}=\left(r+\delta_{i}\right) \frac{p_{i}^{I}}{m c_{i}}
$$

where $g_{i}$ is the production function depicted in Figure 1, $m c_{i}$ the marginal cost, $r$ the real interest rate, $\delta_{i}$ is the depreciation rate, and $p_{i}^{I}$ is the price of the investment good used in sector $i$ (the investment good is assumed to be a Leontief composite of goods from different sectors). As the shadow price of capital is $p_{i}^{I}$, the value of total capital stock is given by:

$$
V=\Sigma_{i} p_{i}^{I} K_{i}
$$

On the supply side of the capital market, savings result from intertemporal

\footnotetext{
${ }^{6}$ Building an intertemporal CGE model with rational expectations (see Keuschnigg and Kohler, 1996) have necessitated important simplifications in the model structure (imperfect competition, etc) that are not justified in the present case.
} 
optimization by a representative individual with finite life expectancy. Following the "perpetual youth" model proposed by Blanchard (1985), we assume that the only uncertainty is the time of death: each individual faces a constant probability of dying, $\gamma$, at any moment in his life (inverse of life expectancy). Thus, at time $t$, the expected utility of an individual born at time $s$ can be written as:

$$
\int_{t}^{\infty} \exp [(\theta+\gamma)(t-\tau)] \frac{c(s, \tau)^{1-1 / \sigma^{T}}}{1-1 / \sigma^{T}}
$$

where $c$ is the individual's consumption expenditures, $\sigma^{T}$ is the intertemporal elasticity of substitution, and $\theta$ is the rate of time preference.

We adopt the usual assumption that individuals contract reverse life insurance. As shown in Appendix A, it turns out that, in the steady state, total nonhuman wealth, $A$, is linked to human wealth, $H$, through a "savings rate", $s$, as follows:

$$
A=s H ; \quad H=\frac{Y^{T}+\left(1+t^{D}\right) Y^{L}}{\gamma+\left(1+t^{D}\right) r}
$$

where $Y^{L}$ is labor income (net of social security contributions), $Y^{T}$ is untaxed net transfer income, $t^{D}$ is the income tax rate. Note that the stock of savings (nonhuman wealth) does not depend on income from capital. The "savings rate" is given by:

$$
s=\frac{\left(1-t^{D}\right) \sigma^{T} r-\sigma^{T} \theta}{\gamma-\left[\left(1-t^{D}\right) \sigma^{T} r-\sigma^{T} \theta\right]} .
$$

Aggregate consumption in the steady-state, $C$, can be derived from human and nonhuman wealth as follows:

$$
C=\left(1-t^{D}\right) r A+\left[\left(1-t^{D}\right) r+\gamma\right] H .
$$

It follows from [9] and [11] that aggregate consumption, and thus the steady-state level of welfare (which neglects the costs of transition), depend ultimately only on human wealth:

$$
C=\left[\left(1-t^{D}\right) r s+\left(1-t^{D}\right) r+\gamma\right] H
$$

Hence the accumulation of nonhuman wealth acts as a human-wealth "multiplier". 
Figure 3. Capital Market Equilibrium.

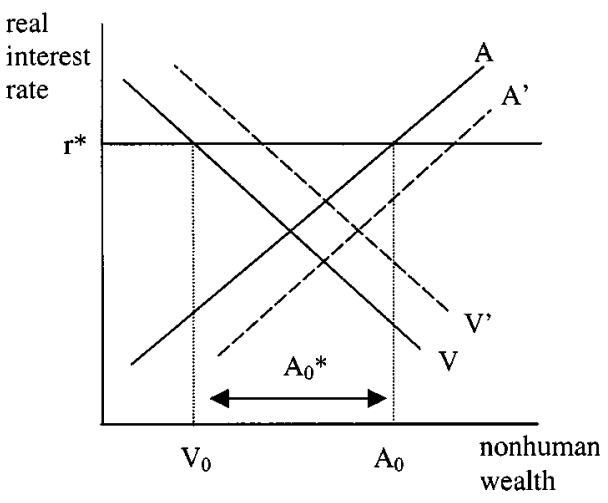

(a) home market

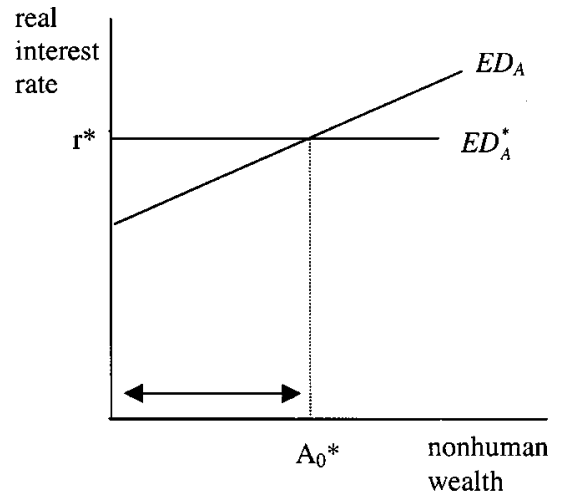

(b) international market

In the case of perfect international capital mobility, agents are indifferent between domestic and foreign assets. Thus interest rates are identical across countries, and total nonhuman wealth in a country is given by $A=V+A^{*}$, where $A^{*}$ are net foreign assets held by residents of the country. Equilibrium in the world capital market is defined by:

$$
\sum_{c} A_{c}^{*}=0
$$

which is the condition that the sum of excess demand for capital across countries is zero.

A graphical representation of capital market equilibrium for a small country is depicted in Figure 3. It is assumed that the country is so small that it faces an infinitely elastic demand (supply) in the world market for financial assets, so that it has no influence on the world interest rate $\left(E D_{A}^{*}=r^{*}\right.$ in Figure 3(b)). In the home market (Figure 3(a)), a long-run demand curve for capital can be derived by inverting equations [6] with respect to $K_{i}$ and by inserting these expressions into [7]. The resulting curve is decreasing with respect to the real interest rate. Domestic capital supply is given by equations [9] and [10] and represented by the upward-sloping curve in Figure 3(a). The stock of net foreign assets, $A_{0}^{*}$, is determined as the difference between capital supply and demand, at the world interest rate. When we simulate the model in a version without capital mobility, the real interest rate is endogenous in each country and net foreign assets are fixed at the initial (calibrated) level. ${ }^{7}$ In this case the "savings rate" $s$ varies positively with the interest rate.

Figure 3 also helps to illustrate the difference between our approach and other 
Table 1. Welfare Changes Under Alternative Scenarios (Percentage of GDP)

\begin{tabular}{|c|c|c|c|c|}
\hline \multirow{2}{*}{$\begin{array}{r}\text { scenario: } \\
\text { version of the model }{ }^{a} \text { : }\end{array}$} & \multicolumn{2}{|c|}{ Bilateral agreements } & \multicolumn{2}{|c|}{ EU accession } \\
\hline & static & dynamic & static & dynamic \\
\hline Market integration & 0.2 & 0.4 & 0.5 & 1.2 \\
\hline of which: reduction of NTBs & 0.1 & 0.2 & 0.4 & 0.9 \\
\hline Free movement of persons & 0.1 & 0.6 & 0.1 & 0.6 \\
\hline Total bilateral agreements: & 0.3 & 1.0 & & \\
\hline Fiscal consequences: & & & -1.0 & -1.5 \\
\hline of which: net transfer & & & -1.0 & -1.6 \\
\hline Customs union: & & & 0.8 & 0.7 \\
\hline of which: common agricultural policy & & & 0.7 & 0.6 \\
\hline Monetary union & & & & 1.1 \\
\hline of which: interest rate differential & & & & 0.9 \\
\hline Total EU accession: & & & 0.5 & 1.2 \\
\hline Total EU accession cum monetary union: & & & & 2.5 \\
\hline
\end{tabular}

Notes: ${ }^{a}$ Capital assumed to be perfectly mobile internationally in the dynamic case

steady-state models (Baldwin et al., 1995; Harrison et al., 1996). In these models, the savings function is not spelled out explicitly. Thus the equilibrium capital stock is obtained by evaluating total capital demand at a fixed real interest rate. Net foreign assets are assumed to be zero, such that nonhuman wealth, $A_{0}$, is simply equal to the value of the aggregate capital stock, $V_{0}$. This amounts to assuming implicitly that the savings function is a horizontal line, at $r^{*}$. Obviously, the two approaches are likely to yield different results. A policy change, such as a reduction in non-tariff barriers, shifts both curves, to $A^{\prime}$ and $V^{\prime}$ respectively. In the "traditional" approach, only the shift from $V$ to $V$ ' matters; it is driven by the increase in capital demand at given interest rates. By contrast, in the present model human wealth ultimately determines both nonhuman wealth and the steady-state welfare level. Thus steady-state welfare changes are predominantly driven by labor demand, since labor supply is assumed to be perfectly inelastic. ${ }^{8}$

\section{Simulations and Results}

The following simulations are carried out to capture the implications for

\footnotetext{
${ }^{7}$ Since the world interest rate is hardly affected by Swiss membership in the EU, the interest income perceived by Swiss residents on these net foreign assets can be considered as being exogenous. Note that the more natural assumption that net foreign assets are zero would have been very unrealistic in the Swiss case and would not have allowed to compare results with the perfect-capital-mobility version of the model.

${ }^{8}$ Labor supply is supposed to be exogenous, as the introduction of a labor-leisure choice in such models seems to affect only very slightly the welfare outcome of trade liberalization (see de Melo and Tarr,1992).
} 
Switzerland of two broad integration scenarios: the bilateral agreements (BIL) or a full EU accession (ACC). Our preferred estimates are those based on the longrun steady state equilibrium of the model (endogenous capital accumulation), with perfect international mobility of capital, though, for the sake of comparison, results obtained with alternative closures of the capital market (i.e. capital exogenous or endogenous but internationally immobile) are also mentioned whenever they differ markedly from those obtained in the preferred version.

Table 1 summarizes, under two alternative closures (static or dynamic), welfare effects expressed in percentage change with respect to a "status quo" scenario in which Switzerland does not to undertake any unilateral reform. ${ }^{9}$ Discussion will move on from simulations which are common to both integration scenarios (market integration and free movement of persons), to those which are specific to the EU membership case (fiscal consequences, customs union and monetary union). As welfare gains are expressed in terms of differences between two steady states, they fail to include the loss from reduced consumption due to capital accumulation during the transition period. In a sense, this means that our welfare estimates are upper bounds of the true welfare effects (see Baldwin, 1992). However, in the spirit of the overlapping generations framework used here, they may also be interpreted as reflecting, for future (post-adjustment) generations, the difference in welfare between alternative scenarios.

\section{A. Market Integration}

The bilateral negotiations reduce non-tariff barriers (NTBs) in two areas: transport and technical barriers to trade (TBTs). In the simulations, these reductions are modeled by a decrease in trade costs. For the transport sector, we used the estimates of Müller and van Nieuwkoop (1999), for whom the implementation of the "40-tonners" agreement and the "New Transalpine Railway" net should lead to a cost-reduction of $0.3 \%$ of the value of exports. Regarding TBTs, estimates were derived from ex-post studies: the gains from mutual recognition of tests, certificates and approvals in the EU case has been estimated at $0.5 \%$ of export value (Single Market Review,1998). As the scope for standardization is more limited in the Swiss case, and given the important unilateral harmonization efforts undertaken by Switzerland since 1993, only $10 \%$ of this figure has been

\footnotetext{
${ }^{9}$ The base year is 1995 . However, to reflect the results of the Uruguay Round agreement, tariff rates are those applied in 1996. Moreover, VAT rates are raised to $10 \%$, according to the planned adaptation of social security financing.
} 
applied here.

The resulting decrease of NTBs in the BIL scenario $(0.35 \%$ of the value of exports) leads to only modest gains in terms of welfare (between 0.1 and $0.2 \%$ of GDP according to the version of the model, static or dynamic respectively). However, as argued in section 2, standardization and mutual recognition of tests can be expected to increase product substitutability. This is captured in the simulation by a modification of the structure of preferences calibrated on the decrease in price-cost margins estimated by ex-post studies (Allen et al., 1997). Again, to control for the gradual rapprochement between Swiss and EU regulations, only $25 \%$ of the reported decrease in price-cost margins has been used in the calculations (see Table A2 in the Appendix). When added to the previous reduction of NTBs, this increase in product substitutability roughly doubles the welfare impact of market integration in the BIL scenario (this is the line "reduction of NTBs" in Table 1).

The same factors operate in the market integration simulation of the ACC scenario. However, in this case, effects are stronger for two reasons. On the one hand, harmonization is deeper in case of EU membership, as it also recognizes the equivalence of national regulations (known as the "Cassis de Dijon" principle, which covers approximately a quarter of intra-EU trade). Hence, it is not $10 \%$, but $35 \%$ of the original estimates of the Single Market Review that are considered in this simulation. By the same token, the calibration of the modification of preferences (increased substitutability) is based on $50 \%$ (instead of $25 \%$ ) of the reported decrease in price-cost margins estimated by ex-post studies. On the other hand, as for countries in the SMP, additional benefits can be expected, in the ACC scenario,

Table 2. Immigration and Wage Structure: Alternative Versions of the Model (Percentage Change with Respect to the Status Quo)

\begin{tabular}{|c|c|c|c|c|}
\hline $\begin{array}{r}\text { version of the model: } \\
\text { capital internationally: } \\
\text { skill composition of immigrants }{ }^{a} \text { : }\end{array}$ & $\begin{array}{c}\text { static } \\
\text { neutral }\end{array}$ & $\begin{array}{c}\text { dynamic } \\
\text { immobile } \\
\text { neutral }\end{array}$ & $\begin{array}{l}\text { dynamic } \\
\text { mobile } \\
\text { neutral }\end{array}$ & $\begin{array}{c}\text { dynamic } \\
\text { mobile } \\
\text { skill-biased }\end{array}$ \\
\hline Average wage & -1.1 & 0.7 & 0.0 & -0.5 \\
\hline - university & -2.0 & 1.2 & 0.0 & -5.2 \\
\hline - superior education & -1.1 & 0.7 & 0.0 & 0.9 \\
\hline - apprenticeship & -0.8 & 0.6 & 0.1 & 0.6 \\
\hline - compulsory school & -0.5 & 0.5 & 0.1 & 0.6 \\
\hline User cost of capital & 1.4 & -0.9 & 0.0 & 0.1 \\
\hline
\end{tabular}

${ }^{a}$ neutral : identical to the resident population/skill-biased : share of the highest skill category three times larger than in the resident population. 
from the reduction of border controls and transport/insurance costs related to trade. The figures applied in the simulation are based again on estimates of the Single Market Review (1998) and vary across sectors (see Table A2 in the Appendix). ${ }^{10}$

These additional reductions in NTBs lead to a substantial increase in steadystate welfare gains, which reach $1.2 \%$ of GDP in the dynamic version of the model. Of this figure, $0.9 \%$ corresponds to the sole reduction of NTBs, which

Table 3. Aggregate Results Capital Endogenous and Perfectly Mobile Internationally (Percentage Change with Respect to the Status Quo)

\begin{tabular}{|lccc|}
\hline & $\begin{array}{c}\text { Bilateral } \\
\text { agreements }\end{array}$ & EU accession & $\begin{array}{c}\text { EU accession } \\
\text { cum monetary union }\end{array}$ \\
\hline GDP & 2.0 & 2.9 & 2.2 \\
GNP & 2.2 & 3.3 & 3.8 \\
GDP per capita & 0.6 & 1.5 & 0.8 \\
Welfare of residents (\% of GDP) & 1.0 & 1.2 & 2.5 \\
Private consumption & 3.2 & 3.9 & 6.4 \\
Investment & 2.4 & 1.4 & -1.5 \\
Total exports & 0.7 & 8.3 & 3.8 \\
Exports to the EU & 1.7 & 14.5 & 12.2 \\
Exports to the ROW & -1.0 & -1.7 & -9.9 \\
Total imports & 1.8 & 7.9 & 8.3 \\
Imports from the EU & 2.2 & 15.5 & 15.9 \\
Imports from the ROW & 0.0 & -22.2 & -21.7 \\
Capital stock & 2.0 & 1.0 & -2.1 \\
Labor & 1.4 & 1.4 & 1.4 \\
User cost of capital & -0.1 & 0.0 & 4.0 \\
Average wage rate & 0.5 & -0.3 & -2.8 \\
Wage-university & 0.8 & 0.2 & -4.0 \\
Wage-superior education & 0.5 & 0.1 & -2.6 \\
Wage-apprenticeship & 0.5 & -0.5 & -2.3 \\
Wage-compulsory school & 0.5 & -1.4 & -2.5 \\
Labor remuneration (per capita) & 0.5 & -0.4 & -2.6 \\
Capital remuneration (per capita) & 1.6 & 2.3 & 17.5 \\
Disposable income (per capita) & 1.8 & 2.1 & -3.5 \\
Real interest rate & 0.0 & 0.0 & 2.5 \\
Stock of assets & 3.2 & 4.2 & \\
Net foreign assets & 5.4 & 10.2 & -2.1 \\
Real exchange rate & -0.2 & 1.2 & -3 \\
Terms of trade & 0.2 & & -3 \\
\hline
\end{tabular}

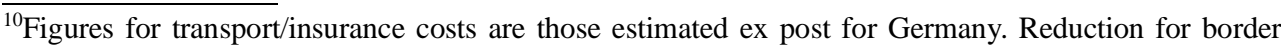
controls correspond to $50 \%$ of the original calculations, as it is estimated that already a half of theses gains were already reaped by the Single Market program.
} 
suggests that the additional impact of product standardization is relatively smaller than suggested by the results of the BIL scenario. ${ }^{11}$

\section{B. Free Movement of Persons}

Although characterized by a long transition period, the bilateral agreements should lead in the long run to the same effect as EU membership: free labor movement between Switzerland and the EU. Given the present wage differentials, Straubhaar (1999) estimates that net immigration flows would add up to 1.0-1.5\% of the resident population. The simulation in Table 1 is based on an exogenous increase of 100'000 immigrants (1.4\% of resident population), both in the BIL and in the ACC scenario.

Here, results depend a lot on assumptions about capital formation. In the static case, welfare gains are limited $(0.1 \%$ of GDP) and wages fall for all skill categories (see Table 2). However, if capital is endogenous and internationally mobile, immigration boosts up investment $(1.9 \%)$, because the marginal productivity of capital increases, and therefore leads to a stronger welfare increase $(0.6 \%$ of GDP), but hardly affects factor prices. If capital is immobile inter-nationally, the investment increase is still larger $(2.7 \%)$, and wages even go up. This wage increase is due to a fiscal externality effect: as it is assumed that the same level of public services can be maintained without additional financing, the larger population allows a lower income tax per capita.

The previous simulation assumes that the skill structure is identical between the resident population and the new immigrants. However, recent surveys from the Statistical Federal Office reveal that Swiss entrepreneurs complain about the lack of skilled workers, suggesting that the "pull-effect" would be particularly strong for skilled migrants. Therefore, the last column of Table 2 shows the wage struc-ture effect of assuming that the share of the highest skill category of migrants is three times larger than in the resident population. As capital and high-skill labor are complementary, this leads to a stronger increase in investment and in welfare $(2.4 \%$ and $0.7 \%$ of GDP respectively, not shown in Table 1), while there is a sharp reduction of the wage rate of the highest skill category that leads to a fall in the average wage.

The cumulative effects of the bilateral agreements yields a modest impact in

\footnotetext{
${ }^{11}$ Another interesting result at the sector level is that the effective decrease in price-cost margins is, on average, about $30 \%$ smaller than the one used in the calibration. This is due to the exit of firms and the implied increase in concentration that mitigates the fall in mark-up (detailed results can be found in Müller and Grether (1999)).
} 
terms of aggregate welfare (1.0\% of GDP, see Table 1) and in terms of income redistribution (factor remuneration per capita increases by $0.5 \%$ for labor and $1.6 \%$ for capital, see Table 3), though the magnitude is close to double in case of EU accession, due to the stronger reduction of NTBs. However, at this stage, the comparison is incomplete as the ACC scenario implies a larger bundle of simulations which are described below.

\section{Fiscal Consequences}

The contribution of Switzerland to the EU budget has been estimated by the Swiss federal administration at $0.88 \%$ of GNP per year. In the simulation, it is financed by an increase in the VAT tax rates (from 10\% to 13\%). On its own, this transfer leads to a considerable welfare loss of $1.6 \%$ of GDP in the dynamic version of the model. There are two secondary burden of the transfer that can only be captured in a general equilibrium framework. First, there is a terms of trade deterioration $(-0.3 \%$, not shown in Table 3$)$. Second, the supply of capital is reduced (through a reduction of $Y^{T}$ in equation [9]), which leads to a decrease in net foreign assets (alternatively to an increase in the real interest rate if capital is assumed to be perfectly immobile internationally).

To comply with the minimum EU level, VAT rates have to be increased further to $15 \%$. It is assumed that the additional resources are used to reduce the direct income tax until the impact on public budget is neutralized. Adding this simulation to the transfer hardly affects the net impact of fiscal consequences on aggregate welfare $(-1.5 \%$ of GDP). However, the reduction of direct taxation promotes saving (which almost cancels out the reduction in net foreign assets), while the increase of VAT reduces the incentive to invest in sectors which are excluded from the VAT base, leading to a decrease in the capital stock $(-1.4 \%)$.

\section{Customs Union}

The adoption of the customs union is simulated by a discriminatory elimination of trade barriers between Switzerland and the EU and by the replacement of Swiss by European trade measures on Swiss imports from the rest of the world. This effect of a discriminatory arrangement is the usual focus of most simulation models (see e.g. the review of Baldwin and Venables, 1995). The largest changes occur in the agricultural and food sectors, which are subject of a separate treatment. Instead of tariffs, a broader measure of protection is used for those products where it is available. It is the ad valorem tariff equivalent of the domestic 
support elaborated by the OECD on the basis of comparisons between domestic and international prices (OECD, 1998).

The degree of tariff and non-tariff protection reflected by these measures appears to be considerably larger in Switzerland than in most other OECD countries. This explains why the adoption of the common agricultural policy (CAP) leads to large welfare gains $(0.6 \%$ of GDP), in spite of the small size of the Swiss agricultural sector. Most of these gains are due to improved resource allocation, as results from the static variant of the model turn out to be of the same magnitude. ${ }^{12}$

For all other commodities, the adoption of the common external tariff (CET) is simply simulated by suppressing all tariffs on Swiss-European trade and by replacing the ad valorem Swiss tariffs on imports from the rest of the world by their EU equivalents. In general, Swiss tariffs on imports from the ROW are lower than tariffs applied by the EU but higher than Swiss tariffs on imports from the EU (this is due to the EU-EFTA free trade agreement, see last two columns of Table A2). ${ }^{13}$

On the whole, the inclusion of non-agricultural and non-food products in the customs union simulation leads to important changes in Swiss trade flows. Imports from the rest of the world decrease by $18.8 \%$, those from Europe rise by $11.2 \%$ while both are increasing, by $2.3 \%$ and $4.5 \%$ respectively, in the CAP case. However, there is only a weak additional welfare increase $(0.1 \%$ of GDP), which suggests that trade creation effects are almost entirely compensated by trade diversion effects.

Cumulating the effects of "deeper" integration gives a "representative" estimate of the aggregate net welfare increase of Switzerland's accession to the EU (1.2\% of GDP). The difference with the BIL scenario appears to be rather small, because of the important welfare loss implied by the Swiss contribution to the EU budget. Indeed, in the ACC scenario, gross welfare gains are almost three times bigger than in the BIL case and, as indicated in Table 3, part of this gain is attributable to improved terms-of-trade. But to get the full impact of EU accession, one should likely add the effects of monetary union.

\section{E. Monetary Union}

If Switzerland were to join the euro-zone, the interest rate would have to adjust to European levels. This is simulated, in the dynamic version of the model (the

\footnotetext{
${ }^{12}$ Note that in the model, agriculture is a constant returns to scale activity while most manufacturing sectors are characterized by increasing returns to scale activities. Hence, releasing resources from agriculture to manufacturing gives rise to scale efficiency gains in manufacturing.

${ }^{13}$ Data on European tariffs are not reported here for reasons of confidentiality.
} 
only one where it makes sense to do so), by the elimination of the interest rate differential, estimated at $0.75 \%$ over the long run by Bärlocher et al. (1999). In terms of Figure 3, this means that initially Swiss firms face a domestic interest rate which is lower than the one obtained by resident savers (a weighted average between the domestic and the international rate). With monetary union the difference vanishes. On the one hand, this leads to a fall in capital stock $(-3.4 \%)$ and in GDP $(-1.1 \%)$, while on the other hand, there is a net steady-state welfare gain of $0.9 \%$ of GDP, which is basically driven by a "wealth effect" reflecting a strong increase in net foreign assets (30.9\%). ${ }^{14}$ Finally, the adoption of a single currency would also lead to a reduction in transaction costs. This is simulated by a further reduction of NTBs of $0.66 \%$ on Swiss-European trade and leads to effects similar to those commented above. ${ }^{15}$

Adding the effects of monetary union to the ACC scenario roughly doubles the estimated welfare gain, though inequality worsens, as per capita labor remuneration decreases by $2.6 \%$ while per capita capital remuneration increases by $19.5 \%$. However, these results must be interpreted with particular caution, since they are derived from the assumption that exchange rate risk is the sole contributor to the interest rate differential between Switzerland and the EU. There are certainly alternative explanations to this phenomenon, such as informational asymmetries or, perhaps more plausibly, "safe heaven" effects, whose incorporation in the model would likely be debatable.

\section{Conclusions}

This paper has developed a simulation model that includes most of the effects that should be captured when a relatively small country enters into a "deep" regional integration arrangement. The distinguishing characteristics include a careful modeling of some of the mechanisms that would operate under monetary integration, as well as of the likely effects of market integration in manufacturing activities and of budgetary transfers. The combination of these effects in a steadystate general equilibrium model also presents clear advantages over the alternative of a piecemeal approach in which general equilibrium repercussions (which turn

\footnotetext{
${ }^{14}$ In terms of figure 3 , this means that the effect of the contraction of the supply schedule driven by the reduction in wages is more than compensated by the increase in the interest rate on savings.

${ }^{15}$ This figure comes from the lower bound estimates of the EC Commission (1990), which is $0.25 \%$ of GDP, applied to the share of bilateral trade with the EU in Swiss GDP (38.1\%).
} 
out to be quantitatively important, at least in the application for Switzerland) would be neglected. Finally, while the application to Switzerland, like most other ones, can only be expected to yield orders of magnitude, perhaps these estimates are more robust than previous ex-ante exercises that could not benefit from expost estimates of the competitive effects of the SMP on price-cost margins in manufacturing activities.

Turning to the application of the model to Switzerland, the estimates suggest an increase of aggregate welfare of around 1\% of GDP whether it chose the bilateral agreements or full EU membership as an integration strategy. While this estimate may appear rather small, one has to remember that Switzerland, thanks to its unilateral harmonization efforts, is today closer to EU legislation than European countries at the beginning of the nineties. This has been taken into account in the simulations, and partly explains the small welfare increase. Moreover, if it seems surprising that the accession scenario (whose scope is a lot wider than the bilateral agreements) does not lead to higher welfare gains, this is due to the Swiss transfer to the EU budget, whose net impact on welfare is neatly captured in the decomposition of EU accession effects.

Of course, it could be argued that the estimated Swiss contribution to the EU, which is based on existing rules, is rather pessimistic as the rules could be modified in favor of Switzerland if entry negotiations were actually resumed. However, it is hardly possible to anticipate the outcome of such negotiations, though these changes in rules could be easily incorporated in the model. On the other hand, in other areas, one could argue on the contrary that scenarios are too optimistic. For example, since 1996, Switzerland has undertaken reforms that make its agricultural policy closer to the PAC. However, the PAC being itself under reform, it is a priori unclear how the incorporation of these changes would affect the result of the accession scenario.

\section{Acknowledgements}

This paper grew out of a research project funded by the Swiss federal government. We thank Jaime de Melo for his detailed comments, Gabrielle Antille, Marc Bacchetta, Richard Baldwin, Joe Francois and Daniel Morales for helpful suggestions and Rolando Alcala, Samuel Guillet and José Ramirez for excellent research assistance. 


\section{References}

Allen, C., M. Gasiorek and A. Smith (1997), Trade creation and trade diversion, Single Market Review, subseries IV, volume 3, European Communities.

Baldwin, R.E. and A.J. Venables (1995), "Regional Economic Integration," in G. Grossman and K. Rogoff eds, Handbook of International Economics, Volume III, chap. 31, Elsevier.

Baldwin, R. E., R. Forslid et J. Haaland (1995), "Investment Creation and Investment Diversion: Simulation Analysis of the Single Market Programme," NBER Working Paper 5364.

Bärlocher, J., B. Schips and P. Stalder (1999), Makroökonomische Auswirkungen eines EU-Beitrittes der Schweiz, série Contribution à la politique économique, Office fédéral du développement économique et de l'emploi, Berne.

Blanchard, O. J. (1985), "Debt, Deficits, and Finite Horizons," Journal of Political Economy, 93, 2, p. 223-247.

Brown, D. K. (1987). "Tariffs, the Terms of Trade and National Product Differentiation." Journal of Policy Modeling, Vol. 9, No 3, 503-526.

EC Commission (1990), "One Market, one Money," European Economy, vol. 44.

Haaland, J. I. and V. D. Norman (1992), "Global production effects of European integration." in L. A. Winters ed., Trade flows and trade policy after '1992', Cambridge University Press.

Hamermesh, D. S. (1993), Labor Demand. Princeton University Press, Princeton.

Harrison, G., T. Rutherford and D. Tarr (1996), "Increased Competition and Completion of the Market in the European Union: Static and Steady State Effects," Journal of Economic Integration, Vol. 11, No. 3, 332-65.

Keuschnigg, C. and W. Kohler (1996), "Commercial Policy and Dynamic Adjustment under Monopolistic Competition," Journal of International Economics, Vol. 40, No. 3 4, 373-409.

Laxton, D., P. Isard, H. Faruqee, E. Prasad et B. Turtelboom (1998), "MULTIMOD Mark III : The Core and Steady-State Models," IMF Occasional Paper 164.

McDougall, R.A., A. Elbehri, and T.P. Truong (1998), "Global Trade Assistance and Protection," The GTAP 4 Data Base, Center for Global Trade Analysis, Purdue University.

De Melo, J. and D. Tarr (1992). A General Equilibrium Analysis of US Foreign Trade Policy. MIT Press, Cambridge.

Mercenier, J. and N. Schmitt (1996). "On Sunk Costs and Trade Liberalization in Applied General Equilibrium,” International Economic Review, Vol. 37, No. 3, 553-572.

Müller, A. and R. van Nieuwkoop (1999). EU-Integration der Schweiz : wirtschaftliche Auswirkungen, série Contribution à la politique économique, Office fédéral du développement économique et de l'emploi, Berne.

Müller, T. and J.-M. Grether (1999). Effets à long terme de l'intégration de la Suisse à 
l'Europa, série Contribution à la politique économique, Office fédéral du développement économique et de l'emploi, Berne.

OECD (1998), Agricultural Policies in OECD countries, OECD, Paris.

Single Market Review (1998), Aggregate results of the single market program, subseries VI, volume 5, European Communities.

Straubhaar, T. (1999). Integration und Arbeitsmarkt: Auswirkungen einer Annäherung der

Schweiz an die Europäische Union, série Contribution à la politique économique, Office fédéral du développement économique et de l'emploi, Berne.

\section{Appendix A: Savings Behavior}

In the overlapping-generations framework of section II.B, we assume that agents agree to leave all their financial wealth $a$ to an insurance company in the case of their death; as a counterpart, they receive $\gamma a$ at each time period until their death (reverse life insurance, see Blanchard, 1985). Population size is normalized to 1 . The intertemporal budget constraint can thus be written:

$$
\dot{a}(s, t)=\left[\left(1-t^{D}\right) r(t)+\gamma\right] a+\left(1-t^{D}\right) y^{L}(s, t)+y^{T}(s, t)-c(s, t)
$$

where a dot designates derivation with respect to time, $y^{L}$ is the individual's labor income (net of social security contributions), $y^{T}$ net untaxed transfer income and $y^{D}$ the direct tax rate. Maximizing [8] in the text subject to [A1] yields the familiar necessary condition:

$$
\frac{\dot{c}(s, t)}{c(s, t)}=\sigma^{T}\left[\left(1-t^{D}\right) r(t)-\theta\right]
$$

From the intertemporal budget constraint and the transversality condition (which is omitted here), the following expression for individual consumption is obtained:

$$
\begin{gathered}
c(s, t)=\frac{a(s, t)+h(s, t)}{\alpha(t)} \\
\alpha(t) \equiv \int_{t}^{\infty} \exp \left[-\int_{t}^{z}\left[\left(1-\sigma^{T}\right)\left(1-t^{D}\right) r(\tau)+\sigma^{T} \theta+\gamma\right] d \tau\right] d z
\end{gathered}
$$

where $h(s, t)$ is an individual's human capital, given by:

$$
h(s, t)=\int_{t}^{\infty} \exp \left[-\int_{t}^{z}\left[\left(1-t^{D}\right) r(\tau)+\gamma\right] d \tau\right]\left[\left(1-t^{D}\right) y^{L}(s, z)+y^{T}(s, z)\right] d z
$$


We assume that labor income is constant over the life cycle, thus $h(s, t)=h(t)$. Aggregate consumption is obtained by summing over generations. Let upper-case letters denote aggregate variables. Hence:

$$
C(t)=\frac{A(t)+H(t)}{\alpha(t)}
$$

where $H(t)=h(t)$ since population size is 1 , and:

$$
A(t)=\int a(s, t) \gamma e^{-\gamma(t-s)} d s
$$

The dynamic behavior of both human and nonhuman wealth is characterized by the following system:

$$
\begin{gathered}
\dot{H}(t)=\left(\left(1-t^{D}\right) r(t)+\gamma\right) H(t)-\left(1-t^{D}\right) Y^{L}(t)-Y^{T}(t) \\
\dot{A}(t)=\left(1-t^{D}\right) r(t) A(t)+\left(1-t^{D}\right) Y^{L}(t)+Y^{T}(t)-C(t) .
\end{gathered}
$$

Finally, in the steady state, as the interest rate is constant, $\alpha$ simplifies to:

$$
\alpha=\frac{1}{\left(1-\sigma^{T}\right)\left(1-t^{D}\right) r+\sigma^{T} \theta+\gamma}
$$

Moreover, setting time derivatives to zero in [A7], and using [A5] yields:

$$
A=\left(\frac{\sigma^{T}\left(1-t^{D}\right) r-\sigma^{T} \theta}{\sigma^{T} \theta+\gamma-\sigma^{T}\left(1-t^{D}\right)-r}\right) H, H=\frac{\left(1-T^{D}\right) Y^{L}+Y^{T}}{\left(1-t^{D}\right) r+\gamma}
$$

which is the aggregate savings equation used in the simulation model (equation [9] in the main text).

\section{Appendix B: Data and Calibration}

The data used for the calibration of the model stem from different sources (for details see Müller and Grether, 1999). The 1990 social accounting matrix for Switzerland was updated to 1995. For the two other regions (EU, ROW), we used the GTAP database, version 4, which is also for 1995 (McDougall et al., 1998). The two data sources were reconciled by retaining, for Swiss imports and exports, data provided by the Swiss customs authorities. However, tariff data refer to 1996 for Switzerland and the EU, because the changes following the Uruguay Round agreement were only introduced in mid-1995. As European data, which come 
Table A1. Calibrated parameters

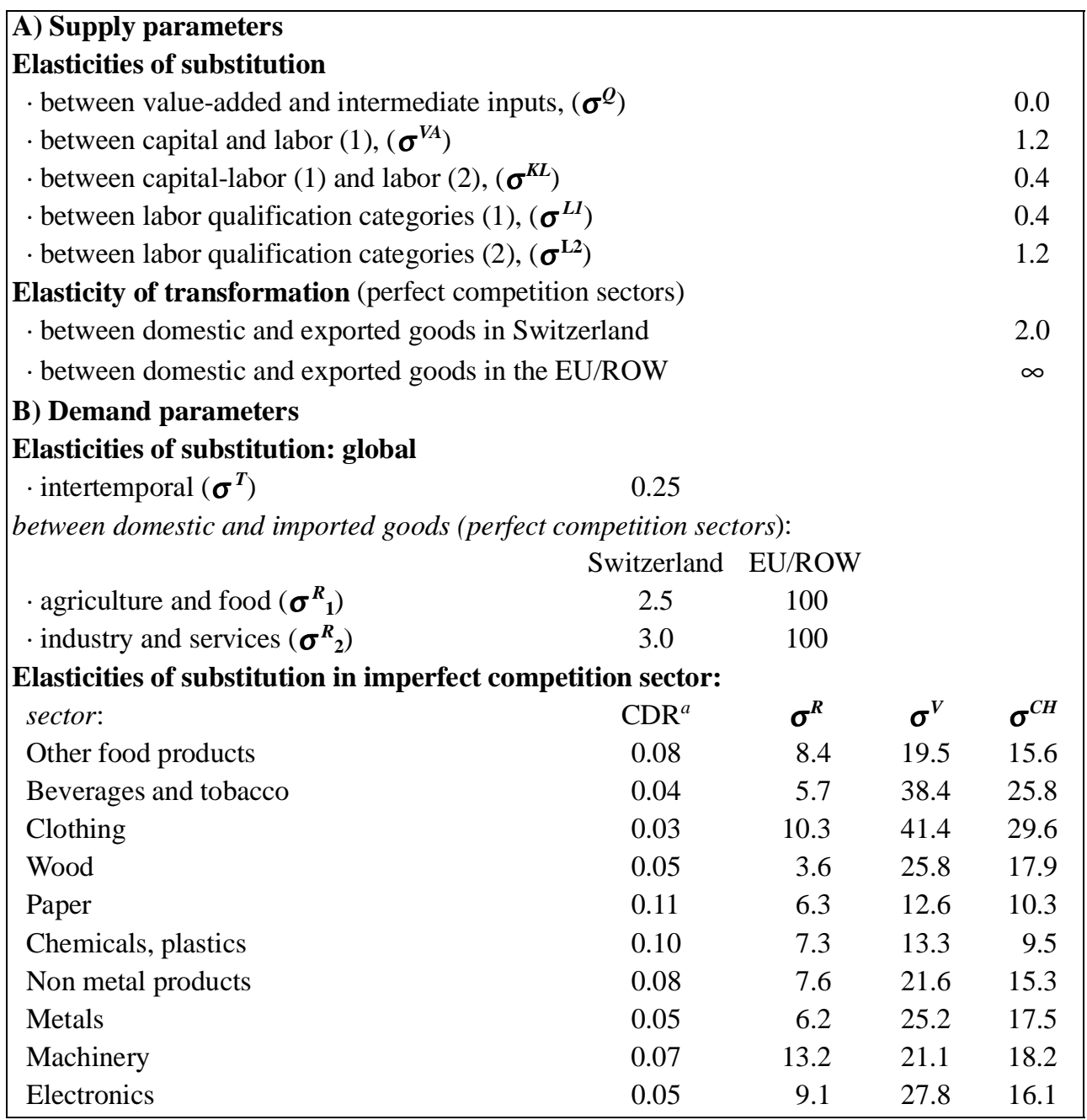

See figures 1 and 2 for a description of the parameters.

${ }^{a}$ Cost disadvantage ratio (share of fixed costs in total cost).

from the Integrated Data Base (IDB) of the WTO, correspond to MFN rates, they were corrected to reflect the free-trade agreement between the EU and Switzerland. Protection data on the agricultural and food sectors are taken from OECD (1998). The calibration procedure is standard, apart from the imperfect competition and savings parameters described below, and from the calculation of Swiss VAT tax rates. 


\section{A. VAT}

In Switzerland, a number of sectors (including agriculture) are excluded from the VAT base. As a result, the usual equivalence with a tax on final consumption disappears. Indeed, let $S$ be the set of all sectors, $S_{i n}\left(S_{e x}\right)$ the subset of sectors included in (excluded from) the VAT base $\left(S_{e x}=S \backslash S_{i n}\right)$, and $I C_{j i}\left(I_{j i}\right)$ the intermediate consumption of (the investment in) good $j$ by sector $i$. Then, using the equality between resources and uses, it is easily shown that VAT collected on good $i$ is given by:

Table A2. Parameters used in the simulations for traded sectors (percentages)

\begin{tabular}{|c|c|c|c|c|c|}
\hline & \multicolumn{2}{|c|}{$\begin{array}{c}\text { Reduction of } \\
\text { non-tariff barriers } \\
(N T B)\end{array}$} & \multirow{2}{*}{$\begin{array}{c}\begin{array}{c}\text { Reduction of } \\
\text { price-cost }\end{array} \\
\text { margins }^{c} \\
(D E S G)\end{array}$} & \multicolumn{2}{|c|}{$\begin{array}{l}\text { Ad valorem tariffs } \\
\text { on imports }^{d} \\
(\text { TARIF F })\end{array}$} \\
\hline & border costs ${ }^{a}$ & $\begin{array}{l}\text { transport } \\
\text { costs }^{b}\end{array}$ & & from the $E U$ & $\begin{array}{c}\text { from the } \\
\text { ROW }\end{array}$ \\
\hline Agriculture & 0.60 & 0.04 & n.a. & 28.83 & 45.21 \\
\hline Electricity, gas, water & 0.45 & 0.06 & n.a. & 0.85 & 0.90 \\
\hline Meat and dairy products & 0.82 & 0.08 & n.a. & 152.41 & 167.30 \\
\hline Other food products & 0.82 & 0.08 & -1.25 & 9.77 & 8.53 \\
\hline Beverages and tobacco & 0.82 & 0.08 & -1.25 & 12.70 & 19.78 \\
\hline Textiles & 0.82 & 0.08 & n.a. & 0.31 & 3.19 \\
\hline Clothing & 0.82 & 0.08 & -0.49 & 2.09 & 9.48 \\
\hline Wood & 0.82 & 0.08 & -1.70 & 0.08 & 0.77 \\
\hline Paper & 0.82 & 0.08 & -1.70 & 0.06 & 0.94 \\
\hline Leather & 0.82 & 0.08 & n.a. & 0.58 & 1.78 \\
\hline Chemicals, plastics & 0.45 & 0.07 & -2.78 & 0.06 & 0.48 \\
\hline Non metal products & 0.77 & 0.08 & -1.83 & 0.09 & 0.81 \\
\hline Metals & 0.80 & 0.08 & -1.70 & 0.08 & 0.53 \\
\hline Machinery & 1.37 & 0.10 & -0.72 & 1.06 & 1.64 \\
\hline Electronics & 1.10 & 0.09 & -2.46 & 0.20 & 0.40 \\
\hline Commerce & 0.50 & 0.08 & n.a. & & \\
\hline Transport & 1.25 & 0.08 & n.a. & & \\
\hline Communication & 1.25 & 0 & n.a. & & \\
\hline Bank and insurance & 1.25 & 0 & n.a. & & \\
\hline Other services (private) & 0.50 & 0 & n.a. & & \\
\hline
\end{tabular}

n.a.: not applicable (perfect competition sectors). ${ }^{a}$ percentage of the value of exports, corresponding to $50 \%$ of the original estimates by Single Market Review (1998). ${ }^{b}$ percentage of the value of exports, corresponding the estimates for Germany by Single Market Review (1998). ${ }^{c}$ (for imperfect competition sectors only) percentage of producer price corresponding to $50 \%$ of the original estimates by Allen et al (1997). ${ }^{d}$ tariffs on agricultural and food sectors: based on border measures estimated by OECD (1998), which reflect the wedge between domestic and international price/tariffs on non agricultural imports: own calculations based on 1996 data provided from Direction Générale des Douanes. 


$$
\begin{cases}t_{i}\left\{C_{i}+\Sigma_{j \in S}\left(I C_{i j}+I_{i j}\right)\right\}-\Sigma_{j \in S_{i n}} t_{j}\left(I C_{j i}+I_{j i}\right) & \text { if } i \in S_{i n} \\ 0 & \text { if } i \in S_{e x}\end{cases}
$$

where $C_{i}$ is final consumption of good $i$ and $t_{i}$ is the VAT rate. Summing over all sectors, total collected VAT becomes:

$$
\sum_{i \in S_{i n}} t_{i}\left(C_{i}+\Sigma_{j \in S_{e x}}\left(I C_{i j}+I_{i j}\right)\right)
$$

which means that in Switzerland, VAT is both a tax on the final consumption of tax-included sectors and a tax on the intermediate consumption and the investments in the tax-excluded sectors. It is in this sense that VAT is modeled and calculated using direct information from fiscal authorities.

\section{B. Imperfect Competition}

The calibration of parameters in imperfect competition sectors is only partly recursive. Fixed costs are calibrated on the basis of estimated cost-disadvantage ratios (CDR), that appear in Table A1, and on observed total output of the sector, $X_{i}^{c}$. Each sector is subdivided in $N_{i}$ symmetric sub-industries (assumed to be equal to 10 in all sectors), while each sub-industry contains $n_{i}^{c}$ identical firms. From the specification of total costs in the main text (equation [1]), and normalizing average cost to 1 in each sector, the aggregate fixed costs at the subindustry level, $F C_{i}^{c}$, are given by:

$$
F C_{i}^{c}=n_{i}^{c} f c_{i}^{c}=\left(\frac{C D R_{i}^{c}}{1-C D R_{i}^{c}}\right) \frac{X_{i}^{c}}{N_{i}}
$$

This leads to the calibration of marginal cost for each firm in the sector:

$$
m c_{i}^{c}=\frac{X_{i}^{c}}{X_{i}^{c}+N_{i} F C_{i}^{c}}
$$

The remaining part of the calibration, regarding the elasticities of substitution in consumption (Figure 2), is based on the simultaneous resolution of a subset of equations. First, the assumption of zero profits implies a relation between fixed costs and markups. It can be shown that the following relation hods:

$$
\sum_{d} M_{i}^{c d} \mu_{i}^{c d}=\frac{N_{i} F C_{i}^{c} m c_{i}^{c}}{1-t_{i}^{c}}
$$

where $M_{i}^{c d}$ are the nominal (observed) imports from country $c$ to country $d, t_{i}^{c}$ is 
the (observed) production tax rate, and $m_{i}^{c d}$ is the markup given by equation [3] in the main text.

Second, we use the econometric estimates by Allen et al. (1998) of the change in markup of domestic firms after the SMP (see Table A2). These changes in markup, which appear in the left-hand-side of equation [5] in the main text, are considered as exogenous in the calibration. Because of the unilateral measures adopted by Switzerland after 1992, $\Delta \mu_{i}^{c d}$ ( $c=d=$ Switzerland) is assumed to be equal to half of the change reported by Allen et al. (1998). These authors did not measure the change in markup on export markets; we assumed that the Swiss exporters' change in markup $\left(\Delta \mu_{i}^{c d}, c=\right.$ Switzerland, $\left.d=E U\right)$ represents 20 percent of the change in markup on the domestic market.

As we focus on Switzerland, the calibration consists then in solving simultaneously equations [3], [5] and [B.5] for $c=$ Switzerland ${ }^{16}$ with respect to $\sigma_{i}^{V}$, $\sigma_{i}^{R}$ and $\sigma_{i}^{C H}$. The number of firms in Switzerland, $n_{i}^{c}$, is estimated by the inverse of the (observed) Herfindahl index. However, because of the non linearity of the system, there is no guarantee that a solution exists. Thus, we relaxed the constraint that the number of firms is exogenous and minimized an objective function formed by the sum of squares of relative deviations of $\sigma_{i}^{V}$, and $\sigma_{i}^{C H}$ and $n_{i}^{c}$. from reference values (given by 5,10,20 and the inverse of the Herfindahl index). Solution values for the elasticities of substitution are given in Table A.1. Finally, given these values, the number of firms in the EU and the ROW is calibrated from the zero profit conditions by using equations [3] and [B.5] with $c=E U$ and $R O W$.

\section{Savings}

Finally, for the calibration of aggregate savings, the value of $A$ in the base year is obtained from estimates of the capital stock plus net foreign assets. Since baseyear values of $Y^{L}$, kn ${ }^{T} d a^{D}$ also observed, while the real interest rate $(r)$ is set to $5 \%$ and the intertemporal elasticity of substitution $\left(\sigma^{T}\right)$ is set to 0.25 , [A.9] can be solved for $\gamma$ (the inverse of life expectancy).

\footnotetext{
${ }^{16}$ More precisely, eqvation [A3] is only considered for $\mathrm{c}=$ Switzerland and $\mathrm{d}=$ Switzerland or EU.
} 